\title{
The Care of SCI Patients in the Developing Nations-Can we stem the rot? *
}

T. K. Shanmugasundaram, MS, MChOrth, FRCS(Eng), FRCS (Edin), FAMS

Professor and Head of Dept. of Orthopaedic Surgery, Madras Medical College and Govt. General Hospital, Madras, India.

\section{Summary}

The aims, objectives and results of the Madras Paraplegia Project at the Government General Hospital, Madras is presented. Eight hundred and forty four Spinal Cord Injury (SCI) patients have been treated in 8 years and 4 months. The Madras Model offers an alternative strategy for the total care of SCI patients. The merits and drawbacks are highlighted. The results to date commend replication of the model in areas of the world where the services for SCI Care are meagre or non-existent.

Key words: Spinal cord injury; Care; The Madras Project; Total care of SCI patients; SCI care in developing countries.

The travails of the care of spinal cord injured patients are well known. Some developed nations in the world have spinal injury centres of excellence, but even in those countries, the services are patchy with large regions without satisfactory facilities for the care of SCI patients. The scene is most depressing in the developing nations of the world, where the care of SCI patients is almost non-existent. Should this situation be allowed to continue? Our experiences at Madras in the last eight years seem to dispel this gloomy picture.

The Madras Model aims at the total care of SCI patients in a General Hospital Set-up. It was started in 1978 as a US aided PL-480 Paraplegia Project. The main aim was the development of simple methods of care for SCI patients in a General Hospital without undue reliance on expensive bed-systems, equipment, etc. with available staff.

The merits of this model are the low-budget, feasibility in any country, the hospital facilities are shared and fewer trained personnel are needed for patient care. It consists of continued care from the acute stage through rehabilitation and vocational placement. There is better care for multiple injured patients as

$\star$ Read at Annual Scientific Meeting of International Medical Society of Paraplegia, Oslo, Norway, June 1986. 
the facilities for such care are available in the teaching hospital. There is active participation of specialists in Orthopaedics, Urology, Plastic Surgery, Neurology, Neuro Surgery, Psychiatry, Physical Medicine Rehabilitation, Bacteriology and Biochemistry at no extra cost. The model is a good training ground for undergraduates, postgraduates, nurses, physiotherapists and other paramedical workers. Clinical research is possible. With some additional funds, recreational and sports activities and the follow-up of the patients can be included.

Eight hundred and forty four SCI Patients have been treated in 8 years and $4 \frac{1}{2}$ months (16.1.1978 to 31.5.1986). It was observed that with a little organisation and devotion, the total care of spinal cord injured patients was possible even in a busy 2000-bedded teaching hospital in Madras, India. Patients admitted within 72 hours of their injury have fared better than those admitted later. The mode of injury in $66 \%$ of the patients was falling from a height or into unprotected wells. The assessment of the neurological status at admission and at discharge revealed a higher percentage of improvement and useful recovery suggesting that the neurological damage to the spinal cord by falls may be of lesser severity than from high velocity injuries resulting from vehicular accidents. With simple techniques of care like the Madras Method of Log Rolling, complications such as pressure sores have markedly decreased compared to their incidence before starting the Paraplegia Project. About $70 \%$ of our surviving patients were ambulant in some manner. There is scope for all round improvement in the working of the Madras Model with additional funding for Staff, provision of recreational and sports activities and follow-up of patients. Psychological and psychiatric assessment at admission and follow-up has been done on 165 patients revealing a wealth of information. It is believed that such studies on SCI patients have not so far been done in a developing nation.

The cost of care of Rs.3716.37 (US Dollars 369.22) for a patient for an average hospitalisation for 75 days (Rs. 49.55 or $\$ 4.92$ per day) must be within the reach of any teaching hospital in any country. The Madras Model is, therefore, commended for trial in the areas of the world where the facilities for the care of SCI patients are meagre or non-existent. 